ISSN: $2594-4827$

\title{
TRABALHO COMO PRINCÍPIO EDUCATIVO: UMA BUSCA PELA DEFINIÇÃO DO CONCEITO E SUA RELAÇÃO COM O CAPITALISMO ${ }^{1}$
}

\author{
Nilton Azevedo de Oliveira Neto ${ }^{2}$ \\ Rosa Oliveira Marins Azevedo ${ }^{3}$ \\ Paulo Henrique Rocha Aride ${ }^{4}$
}

Mais que um substantivo,
Mais que emprego, ocupação,
Trabalho é um termo vivo,
Muito mais que um jargão.
É condição do viver,
É origem do saber,
Está em primeiro plano.
E não há catalogado,
Termo mais apropriado,
Que defina o ser humano.

Nilton Azevedo

\section{RESUMO}

Este artigo teve como objetivo a busca pela definição do conceito de Trabalho como Princípio Educativo e sua relação com o capitalismo, tendo como metodologia a pesquisa bibliográfica. O texto está organizado em três seções. Na primeira, após evidenciar as dificuldades que envolvem a compreensão do termo Trabalho e também a necessidade de uma compreensão correta desse termo, discute-se sobre sua definição dentro da perspectiva metodológica do materialismo histórico-dialético. Essa definição é dada por meio do sentido ontológico, no qual o trabalho é visto como parte do ser dos homens, como uma condição para a produção de sua existência, portanto, imutável e permanente; e por meio do sentido histórico, entendido como o aspecto econômico, o qual ganha diferentes formas, dependo do modelo de organização social. Na segunda seção, analisa-se o conceito de Princípio Educativo do trabalho. Isso se faz por meio da distinção de trabalho entre fato social e princípio pedagógico. Na última seção discutese sobre a relação do trabalho como princípio educativo e o capitalismo, evidenciandose que apesar das limitações quanto à operacionalização do trabalho como princípio

\footnotetext{
${ }^{1}$ Uma versão preliminar desse texto foi apresentada no I Simpósio Amazônico em Educação Profissional e Tecnológica, promovido pelo ProfEPT/IFAM/CMC, realizado em Manaus, Amazonas, nos dias 28 a 29/11/2018.

${ }^{2}$ Estudante do Mestrado em Educação Profissional e Tecnológica do Instituto Federal de Educação, Ciência e Tecnologia do Amazonas. E-mail: nilton.neto1988@ hotmial.com

${ }^{3}$ Doutora em Educação em Ciências e Matemática. Professora do Mestrado em Educação Profissional e Tecnológica do Instituto Federal de Educação, Ciência e Tecnologia do Amazonas. E-mail: rosa.azevedo@ifam.edu.br

${ }^{4}$ Doutor em Biologia Tropical e Recursos Naturais. Professor do Mestrado em Educação Profissional e Tecnológica do Instituto Federal de Educação, Ciência e Tecnologia do Amazonas. E-mail: aride@ifam.edu.br
} 
educativo, este é uma condição necessária para a emancipação do trabalhador e uma proposta para além do capital.

Palavras-chave: Trabalho; Princípio educativo; Educação Profissional e Tecnológica, Capitalismo.

\begin{abstract}
This article aimed to define the concept of Work as an Educational Principle and its relation with Capitalism, having as methodology the bibliographical research. The text is organized in three sections. The first section discusses the Work term definition within the methodological perspective of dialectical historical materialism, as well as highlighting the difficulties involved in understanding the term Work and also the need for a correct understanding of this term. This definition is provided by the ontological sense, in which study is seen as part of the men being, as a condition for production of its existence, therefore immutable and permanent; and through the historical sense, understood as the economic aspect, which takes different forms depending on the social organization model. In the second section, the concept of Work as an Educational Principle is analyzed through the distinction of work between a social fact and a pedagogical principle. In the last section the relation between Work as an Educational Principle and capitalism is discussed, evidencing that despite the limitations on the Work as an Educational Principle operationalization, this is a necessary condition for the worker emancipation and a proposal beyond capital.
\end{abstract}

Key words: Work; Educational Principle; Technological and Professional Education; Capitalism.

\title{
INTRODUÇÃO
}

Este trabalho faz parte das atividades da disciplina Bases Conceituais da Educação Profissional e Tecnológica, do Mestrado Profissional em Educação Profissional e Tecnológica, do Instituto Federal de Educação, Ciência e Tecnologia do Amazonas (IFAM). Trata-se de uma busca em ampliar a compreensão acerca do conceito de Trabalho como Princípio Educativo, uma das bases da Educação Profissional e Tecnológica (EPT).

Por meio de pesquisa bibliográfica, propôs-se a uma busca pela definição da categoria Trabalho, e de seu Princípio Educativo, dentro das perspectivas da EPT. Também se discute sobre o Trabalho como Princípio Educativo e sua relação como o Capitalismo. Assim, o texto está organizado em três seções. 
$\mathrm{Na}$ primeira parte, apresentam-se as dificuldades e a necessidade de uma compreensão correta de trabalho, e então, ocupa-se com os seus sentidos ontológico e histórico. No sentido ontológico, o trabalho é entendido como inerente ao ser dos homens, necessário à produção de sua existência, portanto, uma condição permanente e imutável. O sentido histórico vem explicar as formas como essa existência é produzida, e essas formas são mutáveis, dependendo do modelo de organização social nos diferentes períodos da história.

$\mathrm{Na}$ segunda seção, recorre-se à distinção de trabalho entre fato social e princípio pedagógico. Como fato social ou fato existencial, compreende-se a condição permanente que sempre ocorreu na história, em que o homem para viver, sempre necessitou do trabalho para a sua subsistência e, trabalhando, ele produz conhecimento, ou seja, ele educa-se e educa as futuras gerações. Como princípio pedagógico, significa compreender a relação indissociável entre trabalho ciência e cultura, e só em Marx, o trabalho é elevado a essa categoria.

Por último, discute-se sobre as dificuldades que as relações sociais no modo de produção capitalista impõem à operacionalização do trabalho como princípio educativo. Constata-se que o trabalho, neste modelo de sociedade, acontece de forma alienada, reforçando a ideia de adaptação e impondo limites à discussão emancipatória da educação. E ainda, que a operacionalização do trabalho como princípio educativo reside em uma proposta muito mais ambiciosa, qual seja, uma proposta para além do capital.

\section{O CONCEITO DE TRABALHO}

Para chegar-se à definição do Trabalho com Princípio Educativo, faz-se necessário uma definição clara do termo Trabalho em seus dois sentidos, ontológico e histórico, dentro da perspectiva da EPT.

É comum na atualidade, a associação do trabalho às atividades consideradas negativamente. Assim, expressões cotidianas como essas para referir-se à ação de ir ao trabalho, são comuns: "Estou indo para a batalha!"; "Estou indo para a guerra!" "Estou indo para a luta!”, considerando o trabalho como algo penoso. Dessa maneira, conforme as palavras de Ribeiro (2009, p. 49), “pensarmos em ‘Educação para o trabalho’ ou em 'Trabalho como princípio educativo' a primeira questão com a qual nos deparamos está 
relacionada à condição e percepção do que é trabalho". "Como pode ser educativo algo que é explorado, e na maior parte das vezes, se dá em condições de não escolha? Como extrair positividade de um trabalho repetitivo, vigiado e mal remunerado?" (FRIGOTTO; CIAVATTA; RAMOS, 2005).

Ramos (2017) alerta que é "senso comum", ou seja, é uma tendência na maior parte da sociedade, considerar o trabalho como sinônimo de emprego. Em outro momento, Ramos, juntamente com Frigotto e Ciavatta (2005) mencionam três aspectos que lançam dificuldades sobre a compreensão do trabalho como princípio educativo. Primeiro: a marca da cultura escravocrata na mentalidade empresarial das elites dominantes, por conta da tardia abolição da escravidão no Brasil; segundo: "a visão moralizante do trabalho trazida pela perspectiva de diferentes religiões”. Nesta visão, o trabalho é considerado como castigo, sofrimento e/ou remissão do pecado; terceiro: o fato "de se reduzir a dimensão educativa do trabalho à sua função instrumental didáticopedagógica, aprender fazendo". Com tais considerações, fica evidente que há dificuldades com relação ao entendimento do conceito da categoria trabalho, bem como a necessidade entendê-lo corretamente.

Em contrapartida, com base na abordagem do materialismo histórico-dialético, Ramos, no II Seminário de Alinhamento Conceitual do Mestrado Profissional em Educação Profissional e Tecnológica (2017) afirma ainda que é preciso "desconstruir o senso comum de que trabalho seja sinônimo de emprego e reconhecer que essa ralação entre trabalho e emprego expressa uma forma histórica específica do trabalho nas relações sociais capitalistas". Dessa maneira, o trabalho deve ser compreendido em seus dois sentidos: o sentido ontológico e o sentido histórico, conforme será explicitado a seguir.

A partir do entendimento de que o Sentido Histórico apresenta diferentes formas, isto é, muda de acordo com o tipo de organização social nos diferentes períodos da história e que o Sentido Ontológico é permanente e imutável, será tratado aqui primeiramente deste último e em seguida, do primeiro. Isso com fins puramente didáticos, sem negar que estes dois princípios formam uma unidade.

Ao contextualizarem " $[\ldots]$ a ontologia do ser social desenvolvida por Luckás (1978)" e sua importância para reflexão acerca do trabalho como princípio educativo “no decênio de 1980", em meio às discussões que envolveram a elaboração da 
Constituição de 1988 e da LDB (Lei no 9394/96), Frigotto, Ciavatta e Ramos (2005, p. 3) explicam que:

\begin{abstract}
A questão da ontologia tem uma história antiga na metafísica clássica e está ligada à identidade do ser (o ser é e o ser não é). Na ontologia marxiana, o termo é entendido dialeticamente, indica a objetividade dos seres que são e não são ao mesmo tempo, porque estão em permanente transformação. Somos e já não somos o que éramos há algum tempo. [...] O trabalho é parte fundamental da ontologia do ser social(grifo dos autores).
\end{abstract}

De modo semelhante, Teodoro e Santos (2011, p. 158) explicam: "O trabalho, assim visto, é categoria ontológica da práxis humana em que o ser passa qualitativamente de ser biológico a ser biológico e social pela ação intencional"; Medeiros Neta, Assis e Lima (2016, p. 108) dizem que "o trabalho humano é intencional e consciente, logo inerente à vida humana"; e Saviani (1994, p. 145) mostra que

\begin{abstract}
À medida que determinado ser natural se destaca da natureza e é obrigado, para existir, a produzir sua própria vida, é que ele se constitui propriamente enquanto homem. Em outros termos, diferentemente dos animais, que se adaptam à natureza, os homens têm que fazer o contrário: eles adaptam a natureza a si. O ato de agir sobre a natureza, adaptando-a as necessidades humanas, é o que conhecemos pelo nome de trabalho. Por isso podemos dizer que o trabalho define a essência humana.
\end{abstract}

Diante do exposto, fica evidente que a categoria trabalho considerada em seu sentido ontológico, ou seja, como parte inerente ao ser dos homens, é a condição necessária para sua sobrevivência e subsistência. Além disso, é uma condição permanente, existirá enquanto o homem existir.

É importante destacar também, a "intencionalidade e consciência" do trabalho humano, conforme mencionado. Neste sentido, Pacheco (2012, p. 64) afirma "[...] o caráter teleológico da intervenção humana sobre o meio material". Ou seja, ao contrário dos animais que agem por instinto, o homem o faz com vistas a um fim específico: a satisfação de suas necessidades. Nas palavras de Frigotto, Ciavatta e Ramos (2005, p. 4), “[...] a consciência é a capacidade de representar o ser de modo ideal, de colocar finalidade às ações, de transformar perguntas em necessidades e de dar respostas a essas necessidades". 
Visto o Sentido Ontológico do trabalho, ocupar-se-á, agora, com o seu Sentido Histórico. Enquanto o primeiro sentido recebe sua definição pelo fato de ser impossível a existência e sobrevivência do homem sem a mediação do trabalho entre si e a natureza, o segundo sentido vem explicar a forma como acontece essa mediação, e essas formas, esses modos, mudam de acordo com a organização social nos diferentes períodos da história. Nos dias de hoje, por exemplo, essa forma é o trabalho assalariado. "Esta é a forma específica da produção da existência humana sob o capitalismo" (BRASIL, 2007, p. 46).

Este sentido é muito bem definido por Ramos (2017), quando explica que o sentido histórico do trabalho se refere "às formas específicas, configurada pelas relações sociais de produção". Desta maneira, para um claro entendimento deste sentido, ainda de acordo com a autora, deve-se perguntar:

1) Sobre qual modo de existência falamos?

2) Como o trabalho, então se organiza, pelo menos no seu sentido hegemônico, que dá organização à sociedade?

Isso pode ser ilustrado por Saviani (1994) e Ribeiro (2009), quando mostram algumas formas do Sentido Histórico do trabalho em diferentes momentos dentro da História, conforme apresentado no quadro abaixo.

Quadro 1 - Exemplos de algumas formas do sentido histórico do trabalho.

\begin{tabular}{|c|c|}
\hline $\begin{array}{c}\text { PERÍODO } \\
\text { HISTÓRICO }\end{array}$ & FORMA \\
\hline $\begin{array}{c}\text { Sociedades } \\
\text { primitivas }\end{array}$ & $\begin{array}{c}\text { Trabalho solidário e coletivo } \\
\text { (produção apropriada por todos) }\end{array}$ \\
\hline Idade Antiga & $\begin{array}{c}\text { Trabalho escravo } \\
\text { (Propriedade privada de terra) }\end{array}$ \\
\hline Idade Média & $\begin{array}{c}\text { Trabalho servil } \\
\text { (Propriedade privada de terra) }\end{array}$ \\
\hline Idade Moderna & $\begin{array}{c}\text { Trabalho assalariado } \\
\text { (Capitalismo burguês) }\end{array}$ \\
\hline
\end{tabular}

Fonte: Elaborado com base em Saviani (1994, p.145 - 47) e Ribeiro (2009, p. 49). 
Diante do quadro acima, pode-se dizer que compreender o sentido histórico do trabalho, é compreender o seu sentido econômico, "como forma histórica das relações sociais sob um modo de produção específico" (RAMOS, 2009, p. 3).

Além disso, confirma-se também, que sem a mediação do trabalho, a produção da existência humana se torna impossível. Mesmo as "classes ociosas" que não trabalhavam na época das formas de trabalho escravo e trabalho servil, precisavam do trabalho para viver: o trabalho alheio (SAVIANI, 1994).

Deve-se destacar ainda, que os dois sentidos do trabalho discutidos até aqui formam uma unidade. Enquanto o sentido ontológico traduz-se na necessidade de produzir a existência humana, o sentido histórico traduz-se nos meios de satisfazer essas necessidades.

\title{
O CONCEITO DE PRINCÍPIO EDUCATIVO
}

Recorrendo a Teodoro e Santos (2011, p. 151 e 152), verifica-se uma distinção muito importante para o entendimento do Princípio Educativo do trabalho. Esta consiste em diferenciar o trabalho entre fato e princípio. Dito de outro modo,

\begin{abstract}
A expressão 'trabalho e educação' pode indicar um fato existencial e um princípio pedagógico. $\mathrm{O}$ fato existencial refere-se à íntima relação entre o trabalho e a educação, que sempre ocorreu na história, pois desde que o homem é homem existe reciprocidade entre as atividades voltadas para a sobrevivência humana $\mathrm{e}$ as forma de sua personalidade, valores, gostos, habilidades, competências etc. Enquanto princípio pedagógico, no entanto, o trabalho como fundamento da educação tornou-se tema importante para os pedagogos e eixo principal da teoria educacional marxista a partir do surgimento da indústria e do aparecimento dos movimentos socialistas (NOSELLA, 2007, p. 138, grifos do autor).
\end{abstract}

Teodoro e Santos (2011, p. 152) afirmam também que "o trabalho como fato social sempre promoveu aprendizagem, mas quando Marx o elevou à categoria de princípio, a ciência pedagógica foi chamada à cena”.

Para uma discussão acerca da primeira distinção, ou seja, o trabalho como fato social, ou existencial como diz Nosella, é necessário que se compreenda, com base em Saviani (1994; 2007), os fundamentos históricos da relação trabalho-educação, especialmente na época das sociedades primitivas, “[...] quando tudo era feito em comum: os homens lidando com a terra, lidando com a natureza, se relacionando uns 
com os outros, os homens se educavam e educavam as novas gerações” (1994, p. 145). Neste sentido, o autor demonstra que a educação é uma consequência natural do processo de trabalho, quer o trabalhador tenha uma consciência prévia disso ou não.

Esta acepção de trabalho está intimamente relacionada com o seu sentido ontológico. É fato que o homem só pode produzir sua existência por meio do trabalho; é fato que, ao trabalhar, ele produz conhecimento; e é fato também que, produzindo conhecimentos, o homem educa-se e educa as futuras gerações. No entanto, enquanto fato social, o que motiva a prática do trabalho não é a intenção de produzir conhecimentos, mas a de satisfazer as suas necessidades. É educativo porque “[...] a dimensão ontológica do trabalho é, assim, o ponto de partida para a produção de conhecimentos e de cultura pelos grupos sociais" (PACHECO, 2012, p. 64). Nas palavras de Titton (2008, p. 5),

Considera-se, pois, a prática o fundamento do conhecimento, pois o homem só conhece o que é objeto ou produto de sua atividade e só o conhece porque atua praticamente. Entretanto, não qualquer prática, mas fundamentalmente o trabalho.

A segunda acepção, que trata o trabalho como princípio pedagógico,pode ser vista em Ramos (2009, p. 3), quando afirma: “Compreender a relação indissociável entre trabalho, ciência e cultura significa compreender o trabalho como princípio educativo", o que caminha para a direção de uma "[...] educação para o trabalho em que o norte da formação seja a inclusão social, laboral e política dos sujeitos, numa perspectiva integrada" (MEIDEIROS NETA; ASSIS; LIMA, 2016, p.108). Teodoro e Santos (2011, p. 152) complementam dizendo que "[...] desde o seu nascimento, este princípio quer indicar a superação de uma condição comum à formação de uma parcela da sociedade, a dos trabalhadores [...] voltada à formação para o emprego ou ainda para uma especificidade da tarefa do mundo produtivo".

Essa "condição comum à formação dos trabalhadores", ou dito de outro modo, essa formação fragmentada, com vistas apenas para uma forma histórica específica do trabalho, ocorreu a partir da propriedade privada, que levou à divisão de classes, o que resultou na divisão da educação. Uma destinada para as classes dirigentes, outra destinada para a classe dirigida, a classe trabalhadora, conforme explica Saviani (2007, p. 155-158). Ainda, essa dualidade "reflete a divisão que se foi processando entre trabalho manual e trabalho intelectual". E como a escola surge da, e para as classes 
dirigentes, constitui-se num instrumento de liderança militar e liderança política. Assim, a educação escolar consolida-se como destinada à formação intelectual, em detrimento da formação manual da classe trabalhadora.

Conclui-se que o trabalho enquanto princípio pedagógico pressupõe uma consciência da dualidade entre este e a educação e as consequências que isso acarreta. Mas não apenas isso, como também uma intenção de superação desta dualidade com vistas à emancipação do trabalhador da qualidade de alienação imposta por ela.

\section{O TRABALHO COMO PRINCÍPIO EDUCATIVO E O CAPITALISMO ${ }^{5}$}

Após a discussão acerca do conceito de trabalho em seus sentidos ontológico e histórico, e de seu princípio educativo, tanto como fato quanto como princípio, o texto direciona-se agora a uma reflexão acerca do Trabalho como Princípio Educativo na sociedade capitalista.

Deve-se começar reconhecendo que "[...] não é fácil para aqueles que 'vivem do trabalho', que precisam garantir sua sobrevivência, sejaempregado, subempregado ou desempregado, compreender a ideia do princípio educativo do trabalho" (GOMES et al. 2014, p. 258). Visto que "O trabalhador transformou-se numa mercadoria e terá muita sorte se puder encontrar um comprador” (MARX, 2006, p. 66 ApudGOMES et al.2014, p. 258).

Soares e Trindade (2008, p. 1) desenvolvem uma discussão neste sentido a partir de três questionamentos:

[...] o trabalho pode permanecer no capitalismo como princípio educativo? No sistema capitalista quando o trabalhador percebe que é explorado, a própria condição de exploração o educa, porém propicia a emancipação ou somente a adaptação? Se o trabalho como princípio educativo não é possível no capitalismo, qual é o sentido da tentativa da escola recuperar a relação entre conhecimento e a prática do trabalho?

\footnotetext{
${ }^{5}$ Capitalismo é entendido aqui sob a perspectiva histórica de Marx, como modo de produção de mercadorias gerado historicamente desde o início da Idade Moderna, alcançando sua forma plena no desenvolvimento da Revolução Industrial. Por modo de produção, entende-se tanto o modo pelos quais os meios necessários à produção são apropriados como as relações que se estabelecem entre os homens a partir de suas vinculações ao processo produtivo. Sob esta perspectiva, a força de trabalho também se transforma em mercadoria. Logo, a existência do capitalismo implica também a existência de duas classes sociais: uma que detém os meios de produção e outra que tem na venda de sua força de trabalho sua única forma de subsistência (CATANI, 1983, p. 8 e 9).
} 
As análises construídas até aqui evidenciam duas hipóteses, que serviram de orientação para o texto. Na primeira hipótese,

[...] o trabalho se constitui como princípio educativo, considerando a educação em seu duplo sentido - de adaptação e de emancipação [esta última ligada ao sentido ontológico, a primeira ao sentido histórico sob a forma do capitalismo] - por ser práxis que comporta, como um de seus fundamentos, a integração entre ciência, cultura e trabalho (SOARES; TRINDADE, 2008).

Na segunda hipótese, onde se "[...] considera a dimensão histórica da sociedade capitalista [...] o trabalho assume a dimensão de alienação, pois o resultado do trabalho é a mercadoria que não pertence ao trabalhador" (SOARES; TRINDADE, 2008, p. 2).

Percebe-se que os questionamentos feitos pelas autoras, trazem consigo, de modo implícito, um "não" como resposta, isso considerando apenas o sentido histórico do trabalho sob o modo de produção capitalista. Em contrapartida, considerando o sentido ontológico do trabalho, é possível vislumbrar positividades.

Essas positividades podem ser abstraídas a partir das próprias perguntas. Em primeiro lugar, o trabalho sempre será educativo, mesmo enquanto fato social, pois o homem o faz de forma consciente e intencional, ainda que no capitalismo, parte dessa consciência e intencionalidade the seja alienada. Em segundo lugar, porque "o trabalhador ao perceber que está sendo explorado, luta por seus direitos, assim o trabalho o educa" (MARX, 1983b, p. 189 apudSOARES; TRINDADE, 2008, p. 8). Ainda que a operacionalização completa do Trabalho Como Princípio Educativo seja difícil de ser vislumbrada na atual conjuntura histórico-social capitalista, ela é uma condição necessária para emancipação do trabalhador.

Em terceiro lugar, qual é o sentido da tentativa da escola recuperar a relação entre conhecimento e a prática do trabalho? Fica evidente que ao se discutir sobre o trabalho com princípio educativo, o que se busca não é pura e simplesmente uma tentativa de integrar trabalho, ciência e cultura, apenas, sem levar em conta ou apesar do modelo atual de sociedade. Mas, muito mais que isso, trata-se "[...] de uma proposta pedagógica para além do capital, e que está em gestação nos movimentos de luta social pela emancipação humana" (TITTON, 2008, p. 1). 


\section{CONSIDERAÇÕES FINAIS}

O texto procurou identificar o conceito de Trabalho como Princípio Educativo e sua relação com o capitalismo, analisando o conceito de Trabalho e o conceito de Princípio educativo. Após evidenciar que há dificuldades com relação ao entendimento da categoria Trabalho, decorrendo daí a necessidade de uma correta compreensão desse termo, enveredou-se pelo caminho de sua definição dentro das perspectivas da EPT.

Definido o seu primeiro sentido, o sentido ontológico, verifica-se que trabalho é um conceito muito mais abrangente e significativo que simplesmente emprego. Sendo inerente ao ser dos homens, é a condição necessária para a produção de sua existência. Está em primeiro plano. É a partir da prática do trabalho que o homem ganha vida e a qualidade de ser puramente biológico para ser biológico e social. Além disso, como condição para a sua existência, ela é imutável e permanente.

A partir da definição do segundo sentido de trabalho, o sentido histórico, verificase a sua dimensão econômica, e que esta ganha forma específica de acordo com o modelo de organização social. Desta forma, é uma condição mutável subordinada à "[...] forma histórica das relações sociais sob um modelo de produção específico" (RAMOS, 2009, p. 4).

Ao distinguir o trabalho entre fato e princípio, fica evidente que o conhecimento é sempre uma consequência natural do trabalho. Na acepção do trabalho enquanto fato, o conhecimento é produzido mesmo sem uma intenção ou consciência prévia do trabalhador. Já na segunda acepção, o trabalho é elevado à dimensão da consciência de um propósito que se concretize por meio da indissociabilidade entre trabalho, ciência e cultura.

Por fim, ao analisar a relação do trabalho como princípio educativo associado ao capitalismo constata-se que apesar da alienação que acontece nesse modelo de organização social, o trabalho como princípio educativo é uma condição necessária para a emancipação do trabalhador, constituindo-se uma proposta para além do capital. 
ISSN: $2594-4827$

\section{REFERÊNCIAS}

BRASIL. MEC. Educação Profissional Técnica de Nível Médio Integrada ao Ensino Médio. Documento base. Brasília, 2007.

CATANI, Afrânio Mendes. O que é capitalismo. São Paulo: Editora Brasiliense, 1981. (Coleção Primeiros Passos, 4).

FRIGOTTO, Gaudêncio; CIAVATTA, Maria; RAMOS, Marise Nogueira. O trabalho como princípio educativo no projeto de educação integral de trabalhadores. In: COSTA, Hélio da; CONCEIÇÃO, Martinho da. (Org.). Educação Integral e Sistema de Reconhecimento e Certificação Educacional e Profissional. São Paulo: CUT, 2005, v. 1, p. 19-62. Excertos disponível em: <www.escolanet.com.br/teleduc/.../Trabalho_Princip_Educativo.doc.>. Acesso em: 22, ago. 2018.

GOMES, Marco Antônio de Oliveira et al. O trabalho como princípio educativo: a atualidade da educação politécnica. Revista Exitus. v. 4. n. 1. Jan/jun. 2014.

MEDEIROS NETA, Olívia Morais; ASSIS, Sandra Maria; LIMA, Aline Cristina Silva. O trabalho como princípio educativo: uma possibilidade de superação da dualidade educacional no ensino médio integrado. Revista Ensino Interdisciplinar, v. 2, no . 05, Julho/2016, UERN, Mossoró, RN.

PACHECO, Eliézer (Org.). Perspectivas da educação Profissional Técnica de Nível Médio:

Proposta de diretrizes curriculares nacionais. São Paulo: Fundação Santillana Moderna, 2012.

RAMOS, Marise Nogueira. Trabalho e formação profissional na Educação Profissional e Tecnológica. In: II Seminário de Alinhamento Conceitual do Mestrado Profissional em Educação Profissional e Tecnológica (ProfEPT), 2017. [Vídeo]. Disponível em: <https://www.youtube.com/watch?v=gvanEtwJvAU >. Acesso em: 18 ago. 2018.

RAMOS, Marise. Concepção do ensino médio integrado. In: ARAÚJO, Ronaldo; TEODORO, Elinilze. (Org.). Ensino Médio Integrado no Pará como Política Pública. Belém: SEDUC-PA, 2009, p. 144-182.

RIBEIRO, Ricardo. O Trabalho como Princípio Educativo: algumas reflexões. Saúde e Sociedade, v.18, supl. 2, 2009.

SAVIANI, Dermeval et al. O trabalho como princípio educativo frente às novas tecnologias. Novas tecnologias, trabalho e educação: um debate multidisciplinar. Petrópolis: Vozes, p. 147-164, 1994. 
SOARES, Solange Toldo; TRINDADE, Jussara das Graças. O trabalho como princípio educativo e sua dupla dimensão no capitalismo. In: SEMINÁRIO DO TRABALHO, 6. 2008, Marília-SP. Anais... Marília - SP: Gráfica Massoni, 2008.

TEODORO, Elinilze Guedes; SANTOS, Rosineide Lourinho. Trabalho como princípio educativo na educação profissional. Revista de C. Humanas, v. 11, n. 1, p. 151-162, jan./jun. 2011.

TITTON, Mauro. O princípio educativo do trabalho e o trabalho enquanto princípio educativo: ampliando o debate com os movimentos de luta social. In: Anais...Reunião Anual da ANPED, 31., 2008, Caxambú. Constituição Brasileira, Direitos Humanos e Educação, 2008. v. 1. p. 1-13. 